\title{
Bone Mineral Density in Moroccan Patients with Juvenile Idiopathic Arthritis
}

D El Badri ${ }^{*}$, S Rostom ${ }^{1}$, I Bouaddi ${ }^{1}$, A Hassani $^{1}$, B Chkirate ${ }^{2}$, B Amine ${ }^{1}$ and N Hajjaj-Hassouni ${ }^{1}$

${ }^{1}$ Department of Rheumatology, El Ayachi Hospital, University Hospital of Rabat-Sale, Morocco

${ }^{2}$ Department of Pediatrics, Children's Hospital, University Hospital of Rabat-Sale, Rabat, Morocco

\begin{abstract}
Aim: The aim of this study was to evaluate the bone mineral density (BMD) in Moroccan patients with juvenile idiopathic arthritis and its correlates with disease parameters and vitamin D status.

Methods: Forty patients with juvenile idiopathic arthritis (JIA) were included in a cross-sectional study. The diagnosis of JIA was made according to the criteria of the International League of Association of Rheumatology (ILAR). Information on disease activity, quality of life, sex, age, age at diagnosis, duration of medication use and bone fractures were collected by use of a standardized questionnaire. Patients underwent anthropometric assessment, puberty staging and BMD assessment by dual energy X-ray absorptiometry of the lumbar spine, and total body. Bone mineral density (in $\mathrm{g} / \mathrm{cm}^{2}$ ) was expressed in Z-scores, the number of standard deviation above or below the mean value of an age- and sex-matched reference population. In children, low BMD was defined as a Z-score less than -2 and osteoporosis was defined as a Z-score less than-2 with a fracture history. The daily intake of calcium was determined by the translated version in Moroccan Arabic language of Fardellone questionnaire. Laboratory evaluations included serum calcium, phosphate, alkaline phosphatase, 25-hydroxyvitamin D were assessed.

Results: Forty children with JIA were included (22 male, 18 female); the mean of age of the patients was $11 \pm$ 4.23 years. The median of disease duration was 2 years [1-5]. Eighteen (45\%) patients had polyarticular JIA and $60 \%$ used corticosteroids. Twenty patients $(50 \%)$ were given a diagnosis of low BMD and no patient was given a diagnosis of osteoporosis. Bone mineral density $Z$ score in lumbar spine showed a statistically significant correlation with cumulative dose of corticosteroids $(\beta=-0.40, p=0.05)$ and systemic subtype of JIA $(\beta=-1.07, p=0.01)$ and the BMD in total body showed a statistically significant correlation with weight $(\beta=0.40, p=0.009)$ and height $(\beta=0.37$, $p=0.01$ ). However, there was no significant association in our study between the BMD and disease duration, daily intake of calcium, and 25-hydroxyvitamin D.
\end{abstract}

Conclusion: This study suggests that osteopenia was a frequent complication of JIA and it was associated to systemic subtype of JIA, height and cumulative dose of corticosteroids.

Keywords: Bone mineral density; Juvenile idiopathic arthritis; Bone fractures; Vitamin D deficiencies

\section{Introduction}

Juvenile idiopathic arthritis (JIA) is characterized by the onset of arthritis prior to the age of 16 years; it's one of the commonest rheumatic diseases of children and an important cause of short- and long-term disability [1-4]. As a consequence of the disease and of corticosteroid treatment, children with JIA are at increased risk for osteopenia and osteoporosis, putting them at increased risk of fractures [5]. Several studies (mainly cross-sectional) have demonstrated reduced BMD or bone mineral content (BMC) in children and adolescents with JIA [6]. The precise mechanisms that JIA produce osteopenia in these children are not completely understood $[7,8]$. Previous studies have shown that osteoporosis in JIA has a multifactorial origin [8-10]. Reduced or absent physical activity, decreased production of endogenous vitamin $\mathrm{D}$ and drug treatment, especially steroid treatment, are thought to be possible mechanisms of osteoporosis in children with JIA [7-9]. In a study conducted in Moroccan patients with JIA suggests that functional status was disabled and the majority of these patients had active disease after median disease duration of 15 years [11]. To our knowledge, very few studies have focused on the assessment of bone mineral density and vitamin D status in patients with JIA in the Maghreb countries. The aim of our study was to assess bone mineral density (BMD) in Moroccan children and adolescent with JIA and to identify factors playing role in bone mineral disturbance.

\section{Material and Methods}

\section{Patients}

This cross-sectional study was carried out in the Department of Rheumatology and Pediatrics of the University Hospital of Rabat-Sale, Morocco. Study group was composed patients with JIA. The diagnosis of JIA was made according to the criteria of International League of Associations for Rheumatology (ILAR) [12]. Patients with any other chronic disease (endocrinal, neurological, cardiac and renal) were excluded from the study.

A questionnaire was completed based on the information obtained from the patients' medical records and by interviewing all of the participants or their parents. Collected data included age, sex, antecedent of fracture, Subtype of JIA and mean daily corticosteroid

*Corresponding author: Dr. Dalal EL Badri, Department of Rheumatology, E Ayachi Hospital, University Hospital of Rabat-Sale, Morocco, Tel: 0021266231 64 62; E-mail: dalal_dr@yahoo.fr

Received May 08, 2014; Accepted June 10, 2014; Published June 20, 2014

Citation: El Badri D, Rostom S, Bouaddi I, Hassani A, Chkirate B, et al. (2014) Bone Mineral Density in Moroccan Patients with Juvenile Idiopathic Arthritis. Arthritis 3: 131. doi:10.4172/2167-7921.1000131

Copyright: $\odot 2014$ El Badri D, et al. This is an open-access article distributed unde the terms of the Creative Commons Attribution License, which permits unrestricted use, distribution, and reproduction in any medium, provided the original author and source are credited. 
dose at the time of study The cumulative dose of corticosteroids, disease duration, requirement for and duration of other medications (methotrexate, salazopyrine, non-steroidal anti-inflammatory drugs (NSAIDs), Calcium and vitamin D supplementation), disability by the Moroccan version of CHAQ (Childhood Health Assessment Questionnaire) [13].

Height and weight of the children were measured and recorded by the same observer using the same measurement device and height standard deviation score (Height SDS=Measured height-Normal height for age and sex/Standard deviation) and body mass index [BMI=Body weight $(\mathrm{kg}) /$ Height $2\left(\mathrm{~m}^{2}\right)$ ] were calculated.

The puberty status (pre- or postpubertal) was determined by using Tanner stage (from 1 to 5). The daily intake of calcium was determined by Fardellone questionnaire [14] translated and validated into Arabic language.

The disease activity was scored using the tender and swollen joint counts, disease activity score (DAS 28) [15] for polyarticular and oligoarticular JIA, the Maastricht AS Enthesitis Score and Bath AS Disease Activity Index (BASDAI) for Enthesitis-related arthritis [16], patient assessment of pain and global disease activity, physician assessment of global disease activity, erythrocyte sedimentation rate (ESR) and C-reactive protein (CRP).

\section{BMD measurement}

All BMD measurements were obtained with the same Dual Energy X-ray (DEXA) instrument (Lunar Prodigy; GE Lunar, Madison, WI).

Bone mineral density was measured in the lumbar spine (L1L4) and total body. The values were transformed into $Z$ scores by comparing them with age- and sex-specific reference values for this equipment $[17,18]$. According to the International Society for Clinical Densitometry recommendations osteoporosis was defined as a Z-score less than -2 with a fracture history. Low BMD was defined as a Z-score less than -2 without a significant fracture history and osteoporosis was defined as a Z-score less than -2 with a fracture history [19].

\section{Biochemical parameters}

Serum concentrations of calcium, phosphate, alkaline phosphatase and 25-hydroxyvitamin D (25-OH-vitamin D) were measured. Vitamin D levels were classified as normal $(>30 \mathrm{mg} / \mathrm{ml})$, insufficient $(<30, \geq 10 \mathrm{mg} / \mathrm{ml})$ and deficient $(<10 \mathrm{mg} / \mathrm{ml})$.

\section{Statistical analysis}

Statistical analysis was performed using a software program (SPSS for Windows, Version 13.0, SPSS Inc, Chicago, IL). The data were expressed as the mean \pm SD for continuous variables and as frequency (\%) for categorical variables. Descriptive statistics were used to assess the demographic and clinical characteristics of the patients. The association between different variables and BMD in lumbar spine and in total body was investigated by use of univariate and multivariate linear regression. $\mathrm{P}$ values less than 0.05 were considered significant.

\section{Results}

Among the 40 patients with JIA, 18 (45\%) were female and 22 (54\%) were male, eighteen patients had polyarticular, nine patients had oligoarticular, and eleven had systemic subtype of the disease. Twelve of the patients were at prepubertal and eight were at postpubertal period. The socio-demographic and clinical characteristics of the patients are presented in table 1 .

\begin{tabular}{|c|c|}
\hline Females Sex ${ }^{1}$ & $18(45)$ \\
\hline Age (years ${ }^{3}$ & $11 \pm 4.23$ \\
\hline \multicolumn{2}{|l|}{$\mathrm{BMI}^{1}$} \\
\hline Obese & $6(15)$ \\
\hline Adequate & $23(57.5)$ \\
\hline Underweight & $11(27.5)$ \\
\hline \multicolumn{2}{|l|}{ Subtype of AlJ' } \\
\hline Systemic-onset arthritis & $11(27.5)$ \\
\hline Oligoarthritis & $9(22.5)$ \\
\hline Rheumatoid factor-positive polyarthritis & $17(45.5)$ \\
\hline Rheumatoid factor-negative polyarthritis & $1(2.5)$ \\
\hline Enthesitis-related arthritis & $1(2.5)$ \\
\hline Psoriatic arthritis & $1(2.5)$ \\
\hline ACPA Positive 1 & $6(15)$ \\
\hline Rheumatoid factor positive ${ }^{1}$ & $6(15)$ \\
\hline Time since JIA onset in years ${ }^{2}$ & $2[1-5]$ \\
\hline \multicolumn{2}{|l|}{ Medications used ${ }^{1}$ : } \\
\hline NSAID & $30(75)$ \\
\hline Corticosteroid & $23(57.5)$ \\
\hline Methotrexate & $16(40)$ \\
\hline Salazopyrine & $6(15)$ \\
\hline Biologics & $3(7.5)$ \\
\hline $\begin{array}{l}\text { Ciclosporin } \\
\text { Cumulative dose of corticosteroid in } \mathrm{mg}^{2} \\
\text { Daily intake of Calcium }{ }^{2}\end{array}$ & $\begin{array}{l}1(2.5) \\
10950[5475-21900] \\
312 \mathrm{mg}[236-406]\end{array}$ \\
\hline
\end{tabular}

1: Number and Percentage N (\%); 2: Median and Interquartile Range (IQR); 3 Mean and Standard Deviation; BMI: Body Mass Index; ACPA: Anti-Citrullinated Peptides Antibodies; NSAID: Non-Steroidal Anti-Inflammatory Drugs.

Table 1: Socio-demographic and clinical characteristics of the patients.

\begin{tabular}{|c|c|c|c|c|c|}
\hline \multicolumn{2}{|c|}{$\begin{array}{l}\text { Levels of } 25 \\
\text { hydroxyvitamine D }\end{array}$} & $\begin{array}{l}\text { Deficient } \\
\text { (<10 ng/ml) }\end{array}$ & $\begin{array}{c}\text { Insufficient } \\
(<30, \geq 10 \mathrm{ng} / \mathrm{ml})\end{array}$ & $\begin{array}{c}\text { Normal } \\
(\geq 10 \mathrm{ng} / \mathrm{ml})\end{array}$ & $\mathbf{P}$ \\
\hline \multirow[t]{2}{*}{ lumbar spine } & BMD & $0.54 \pm 0.29$ & $0.64 \pm 0.19$ & $0.63 \pm 0.26$ & \multirow{2}{*}{$\begin{array}{l}0.70 \\
0.86\end{array}$} \\
\hline & Z scores & $-2.12 \pm 0.96$ & $-1.87 \pm 1.20$ & $-1.70 \pm 1.79$ & \\
\hline \multirow[t]{2}{*}{ Total body } & BMD & $0.76 \pm 0.19$ & $0.74 \pm 0.15$ & $0.74 \pm 0.22$ & \multirow{2}{*}{$\begin{array}{l}0.98 \\
0.28\end{array}$} \\
\hline & $Z$ scores & $-1.80 \pm 1.19$ & $-1.97 \pm 0.99$ & $-1.39 \pm 0.82$ & \\
\hline
\end{tabular}

BMD: Bone Mineral Density $\left(\mathrm{g} / \mathrm{cm}^{2}\right)$

Table 2: BMD and $Z$ Scores of Patients according to levels of 25 hydroxyvitamine $\mathrm{D}$

\begin{tabular}{|l|l|c|c|c|c|}
\hline \multicolumn{2}{|l|}{} & Systemic & Oligoarticular & Polyarticular & P \\
\hline \multirow{2}{*}{ lumbar spine } & BMD & $0.50 \pm 0.07$ & $0.65 \pm 0.26$ & $0.69 \pm 0.22$ & $\mathbf{0 . 0 5}$ \\
\cline { 2 - 6 } Total body & Z scores & $-0.63 \pm 0.60$ & $-1.75 \pm 1.81$ & $-1.45 \pm 1.18$ & $\mathbf{0 . 0 5}$ \\
\cline { 1 - 6 } & BMD & $0.63 \pm 0.14$ & $0.74 \pm 0.19$ & $0.81 \pm 0.15$ & $\mathbf{0 . 0 1}$ \\
\cline { 2 - 5 } & Z scores & $-2 \pm 0.69$ & $-1.95 \pm 0.93$ & $-1.62 \pm 1.14$ & 0.52 \\
\hline
\end{tabular}

BMD: Bone Mineral Density $\left(\mathrm{g} / \mathrm{cm}^{2}\right)$

Table 3: BMD and Z Scores of Patients according to subtypes of JIA

Twenty patients $(50 \%)$ were given a diagnosis of low BMD in lumbar spine, and in total body (Z-score $\leq-2)$, and no patient was given a diagnosis of osteoporosis (Z-score $\leq-2$ and a significant fracture history). No patient reported a bone fracture. No significant family history of fractures was present.

Levels of serum calcium, phosphate and alkaline phosphatase were normal in all patients.

A deficiency of $25-\mathrm{OH}$-vitamin $\mathrm{D}(<10 \mathrm{ng} / \mathrm{ml})$ was found in 4 (10\%) patients.

In this group $75 \%$ of the patients had a low BMD. Normal 25-OHvitamin $\mathrm{D}(>30 \mathrm{ng} / \mathrm{L})$ was found in $10(25 \%)$ patients and in this group 3 patients $(33 \%)$ had a low BMD in lumbar spine and two patients (20\%) had a low total body BMD. There was no statistical significant 
difference in BMD in lumbar spine and in total body and 25-OHvitamin $\mathrm{D}$ levels ( $\mathrm{p}$ was respectively at 0.71 and 0.90 ) (Table 2).

The clinical, laboratory, and medication data were entered into univariate analysis for BMD at the lumbar spine, and at the total body. This analysis revealed that BMD in lumbar spine was associated with the subtype of JIA (Table 3), the cumulative dose of corticosteroids, the weight and the height of the patient at the time of DEXA and the BMD in total body was associated with the weight and the height. However, we did not find any statistically significant associations between BMD and the disease duration, and the daily intake of calcium (Table 4 and $5)$.

\section{Discussion}

In the present study, we state the importance of bone loss in Moroccan children with JIA; twenty (50\%) patients had low BMD, in lumbar spine, and in total body. Rusu et al. in a study conducted on 41 child patients found a reduced bone density in $36.5 \%$ patients with JIA [20].

We note a high frequency of osteopenia in our study and this may be explained by the frequent use of corticosteroids in our context.

In our study we found a significant relationship between bone loss and the systemic subtype of JIA. It has been reported that in JIA, both synovial-derived and soluble cytokines are involved. Osteopenia or osteoporosis occurs in all of the JIA forms, most typically in systemic and polyarticular forms of disease [21-22]. On the other hand the low bone mass is associated with the high activity of the disease and with the number of involved joints in JIA patients also with the reduction of bone formation $[21,22]$. In our study we didn't find any correlation between ESR, disease activity, disease duration, DAS 28, CHAQ and BMD.

Children with JIA have to take many medications, such corticosteroids that have significant effects on bone and its mineralization $[10,8,23]$. In our sample, the loss of bone mass appears to be associated with cumulative dose of corticosteroids. In JIA, an association between glucocorticoid use and low bone mass was observed in four out of five studies [24,25]. In children a high bone turnover rate and rapid skeletal remodeling are factors that predispose to the rapid occurrence of severe bone loss [26]. Bardare et al. suggested that steroids decrease BMD by means of decreasing 25-OH-Vitamin $\mathrm{D}$ levels [10]. However, in a study by Reed et al. it is suggested that reduced bone mass in patients with JIA is not related to the use of steroids [9].

In our sample, sixty patients $(40 \%)$ were receiving Methotrexate, which is the most frequent Disease-Modifying Anti-rheumatic Drugs (DMARDs) in children. It can cause osteopenia in children patients with malignancies, but low-dose methotrexate used in inflammatory diseases did not influence negatively the bone mass [27,28]. No relation was found with BMD and Methotrexate use in present study.

Weight was a positive contributor to BMD at every site in the present study. The effect of weight on BMD is due to load on weightbearing bones [29]. Therefore, it is recommended that adolescents should maintain sufficient weight and muscle strength through an appropriate diet and physical activity [30].

Several authors have reported that the association of height with bone mass becomes weaker with the progression of pubertal development [31]. In our study, height showed a significant effect on BMD in total body in the present study; however, our results do not support the association between BMD and pubertal stage in children with JIA. The impact of puberty on BMD is described in healthy boys and girls [9,32]. De Schepper et al. proposed that the total increase in BMD during puberty was higher than that during the proceeding 10 years, representing a $40 \%$ increase in BMD during puberty [29]. They also reported that pubertal stage IV is responsible for the most important increase in lumbar spine BMD in both sexes. Van Coeverden et al. reported an increase of up to $60 \%$ in bone mass at all skeletal sites between Tanner stages II and IV [33].

\begin{tabular}{|c|c|c|c|c|c|c|c|c|}
\hline \multirow{4}{*}{ Variables } & \multicolumn{8}{|c|}{ BMD in lumbar spine } \\
\hline & \multicolumn{4}{|c|}{$\mathrm{g} / \mathrm{cm}^{2}$} & \multicolumn{4}{|c|}{ Z scores } \\
\hline & \multirow[t]{2}{*}{$\beta$} & \multicolumn{2}{|c|}{$\mathrm{Cl}$ at $95 \%$} & \multirow[t]{2}{*}{$\mathbf{P}$} & \multirow[t]{2}{*}{$\beta$} & \multicolumn{2}{|c|}{$\mathrm{Cl}$ at $95 \%$} & \multirow[t]{2}{*}{$\mathbf{P}$} \\
\hline & & Lower limit & Upper limit & & & Lower limit & Upper limit & \\
\hline Age & 0.38 & 0.008 & 0.039 & 0.003 & -2.27 & -0.06 & 0.14 & 0.44 \\
\hline Weight & 0.36 & 0.004 & 0.012 & 0.0001 & -2.99 & 0.009 & 0.061 & 0.009 \\
\hline Height & 0.082 & 0.17 & 0.65 & 0.001 & -3.4 & -0.46 & 2.8 & 0.156 \\
\hline Disease duration & 0.62 & -0.022 & 0.027 & 0.84 & -1.42 & -0.26 & 0.016 & 0.07 \\
\hline Daily intake of calcium & 0.61 & 0.0001 & 0.0001 & 0.49 & -1.99 & -0.001 & 0.002 & 0.49 \\
\hline Cumulative dose of corticosteroids & 0.61 & 0.0001 & 0.0001 & 0.84 & -1.46 & 0.0001 & 0.0001 & 0.05 \\
\hline
\end{tabular}

$\mathrm{Cl}$ : Confidence Interval

Table 4: Regression analysis of clinical variables and medications and BMD in lumbar spine.

\begin{tabular}{|c|c|c|c|c|c|c|c|c|}
\hline \multirow{4}{*}{ Variables } & \multicolumn{8}{|c|}{ BMD in Total body } \\
\hline & \multicolumn{4}{|c|}{$\mathrm{g} / \mathrm{cm}^{2}$} & \multicolumn{4}{|c|}{ Z scores } \\
\hline & \multirow[t]{2}{*}{$\beta$} & \multicolumn{2}{|c|}{$\mathrm{Cl}$ at $95 \%$} & \multirow[t]{2}{*}{$\mathbf{P}$} & \multirow[t]{2}{*}{$\beta$} & \multicolumn{2}{|c|}{$\mathrm{Cl}$ at $95 \%$} & \multirow[t]{2}{*}{$\mathbf{P}$} \\
\hline & & Lower limit & Upper limit & & & Lower limit & Upper limit & \\
\hline Age & 0.62 & -0.001 & 0.025 & 0.08 & -2.07 & -0.051 & 0.101 & 0.508 \\
\hline Weight & 0.62 & 0.0001 & 0.007 & 0.03 & -2.67 & 0.007 & 0.046 & 0.008 \\
\hline Height & 0.41 & 0.45 & 0.456 & 0.01 & -2.20 & -0.47 & 1.97 & 0.22 \\
\hline Disease duration & 0.73 & -0.016 & 0.023 & 0.709 & -1.58 & -0.173 & 0.043 & 0.22 \\
\hline Daily intake of calcium & 0.78 & 0.0001 & 0.0001 & 0.49 & -1.86 & 0.0001 & 0.002 & 0.60 \\
\hline Cumulative dose of corticosteroids & 0.69 & 0.0001 & 0.0001 & 0.41 & -1.61 & 0.0001 & 0.0001 & 0.33 \\
\hline
\end{tabular}

Cl: Confidence Interval

Table 5: Regression analysis of clinical variables and medications and BMD in total body. 
In our study the mean calcium intake was $312 \mathrm{mg} /$ day (very inadequate relative to the recommended doses) and $36.4 \%$ of the patients received a calcium supplementation. There was no correlation between BMD and calcium intake or calcium supplementation. Johnston et al. showed that calcium supplementation (1000 mg calcium/day) enhanced the rate of increase in BMD in prepubertal children [34].

In our study levels of calcium, phosphate, and alkaline phosphatase were normal in all patients. A deficiency of $25-\mathrm{OH}$-vitamin $\mathrm{D}(<30 \mathrm{ng} /$ $\mathrm{ml}$ ) was found in $75 \%$ patients but it was not associated to a low BMD in our study.

To our knowledge, the present study is the first to report BMD in Moroccan children with JIA and to describe the possible risk factors associated with decreased bone density in this population.

Our study has some limitations; first we didn't evaluate the effect of activity on BMD although regular exercise which is known to increase BMD in healthy children [35]. Another limitation of our study was the lack of a group of healthy controls but Z-score values below -2 are generally considered a serious warning. Considering the limited sample size in the current study, prospective studies with a group controls are needed to determine the effects of exercise on BMD and fracture risk in JIA and to evaluate the precise relationship between BMD in these patients and disease-related variables.

In conclusion, data obtained from our preliminary study suggest that osteopenia was a frequent complication of JIA. This bone loss in JIA is certainly of multifactorial origin. Our results indicate that underweight was more important factor than others in the development of low BMD in Moroccan patients with JIA. These results should alert clinicians to the potentially high risk for the development of osteoporosis later in life in these patients.

\section{References}

1. Cassidy JT, Petty RE (2005) Chronic arthritis in childhood. In: Textbook of Pediatric Rheumatology, 5th (edn). Cassidy JT, Petty RE (ed`s). Elsevier Saunders, Philadelphia.

2. Singh S (2003) Chronic arthritis: current perspectives. Indian Pediatr 40: 393397

3. Ravelli A, Martini A (2007) Juvenile idiopathic arthritis. Lancet 369: 767-778.

4. Singh S (2004) Collagen vascular disorders. In: Essential Pediatrics, 6th (edn). Ghai OP, Gupta P, Paul VK (eds). CBS Publishers: New Delhi.

5. S Singh, KR Jat (2008) Juvenile idiopathic arthritis: an update Indian Journal of Rheumatology. 3: 110-119.

6. Rabinovich CE (2000) Bone mineral status in juvenile rheumatoid arthritis. J Rheumatol Suppl 58: 34-37.

7. Lepore L, Pennesi M, Barbi E, Pozzi R (1991) Treatment and prevention of osteoporosis in juvenile chronic arthritis with disodium clodronate. Clin Exp Rheumatol 9 Suppl 6: 33-35.

8. Reed A, Haugen M, Pachman LM, Langman CB (1990) Abnormalities in serum osteocalcin values in children with chronic rheumatic diseases. J Pediatr 116: 574-580.

9. Hopp R, Degan J, Gallagher JC, Cassidy JT (1991) Estimation of bone mineral density in children with juvenile rheumatoid arthritis. J Rheumatol 18: 12351239.

10. Bardare M, Bianchi ML, Furia M, Gandolini GG, Cohen E, et al. (1991) Bone mineral metabolism in juvenile chronic arthritis: the influence of steroids. Clin Exp Rheumatol 9 Suppl 6: 29-31.

11. Amine B, Ibn Yacoub Y, Rostom S, Abouqal R, Hajjaj-Hassouni (2010) LongTerm Outcome In Patients With Juvenile Idiopathic Arthritis. J.Orthopaedics 7: 9 .
12. Petty RE, Southwood TR, Manners P, Baum J, Glass DN, et al (2004) International League of Associations for Rheumatology classification of juvenile idiopathic arthritis: second revision, Edmonton, 2001. J Rheumatol 31: 390392.

13. Rostom S, Amine B, Bensabbah R, Chkirat B, Abouqal R, et al. (2010) Psychometric properties evaluation of the childhood health assessment questionnaire $(\mathrm{CHAQ})$ in Moroccan juvenile idiopathic arthritis. Rheumatol Int 30: 879-885.

14. Fardellone P, Sebert JL, Bouraya M, Bonidan O, Leclercq G, et al. (1991) [Evaluation of the calcium content of diet by frequential self-questionnaire]. Rev Rhum Mal Osteoartic 58: 99-103.

15. Ringold S, Chon Y, Nora G. Singer (2009) Associations Between the American College of Rheumatology Pediatric Response Measures and the Continuous Measures of Disease Activity Used in Adult Rheumatoid Arthritis. Arthritis Rheum. 60: 3776-3783

16. Viswanath V, Myles A, Dayal R, Aggarwal A (2011) Levels of serum matrix metalloproteinase-3 correlate with disease activity in the enthesitis-related arthritis category of juvenile idiopathic arthritis. J Rheumatol 38: 2482-2487.

17. Wacker W, Barden HS (2002) Pediatric reference data for male and female total body and spine BMD and BMC. Meeting of the International Society of Clinical Densitometry; Dallas, USA

18. Bhudhikanok GS, Wang MC, Eckert K, Matkin C, Marcus R, et al. (1996) Differences in bone mineral in young Asian and Caucasian Americans may reflect differences in bone size. J Bone Miner Res 11: 1545-1556.

19. Lewiecki EM, Gordon CM, Baim S, Leonard MB, Bishop NJ, et al. (2008) International Society for Clinical Densitometry 2007 adult and pediatric official positions. Bone. 43: 1115-1121.

20. Rusu TE, Murgu A, Moraru E, Florea MM, Ioniuc I, et al. (2008) [Osteopenia in children with juvenile idiopathic arthritis]. Rev Med Chir Soc Med Nat las 112: 88-93.

21. Henderson CJ, Specker BL, Sierra RI, Campaigne BN, Lovell DJ (2000) Totalbody bone mineral content in non-corticosteroid-treated postpubertal females with juvenile rheumatoid arthritis: frequency of osteopenia and contributing factors. Arthritis Rheum. 43: 531-540.

22. Lien G, Flatø B, Haugen M, Vinje O, Sørskaar D, et al. (2003) Frequency of osteopenia in adolescents with early-onset juvenile idiopathic arthritis: a longterm outcome study of one hundred five patients. Arthritis Rheum 48: 22142223.

23. Cassidy JT, Langman CB, Allen SH, Hillman LS (1995) Bone mineral metabolism in children with juvenile rheumatoid arthritis. Pediatr Clin North Am 42: 1017-1033.

24. Celiker R, Bal S, BakkaloÄŸlu A, Ozaydin E, Coskun T, et al. (2003) Factors playing a role in the development of decreased bone mineral density in juvenile chronic arthritis. Rheumatol Int 23: 127-129.

25. Pereira RM, Corrente JE, Chahade WH, Yoshinari NH (1998) Evaluation by dual X-ray absorptiometry (DXA) of bone mineral density in children with juvenile chronic arthritis. Clin Exp Rheumatol 16: 495-501.

26. Fantini F, Beltrametti P, Gallazzi M, Gattinara M, Gerloni V, et al. (1991) Evaluation by dual-photon absorptiometry of bone mineral loss in rheumatic children on long-term treatment with corticosteroids. Clin Exp Rheumatol 9 Suppl 6: 21-28.

27. Reed A, Haugen M, Pachman LM, Langman CB (1990) Abnormalities in serum osteocalcin values in children with chronic rheumatic diseases. J Pediatr 116: 574-580.

28. Cranney AB, McKendry RJ, Wells GA, Ooi DS, Kanigsberg ND, et al. (2001) The effect of low dose methotrexate on bone density. J Rheumatol 28: 2395 2399.

29. De Schepper J, Derde MP, Van den Broeck M, Piepsz A, Jonckheer MH (1991) Normative data for lumbar spine bone mineral content in children: influence of age, height, weight, and pubertal stage. J Nucl Med 32: 216-220.

30. Naka H, Iki M, Morita A, Ikeda Y (2005) Effects of pubertal development, height, weight, and grip strength on the bone mineral density of the lumbar spine and hip in peripubertal Japanese children: Kyoto kids increase density in the skeleton study (Kyoto KIDS study). J Bone Miner Metab 23: 463-469.

31. Theintz G, Buchs B, Rizzoli R, Slosman D, Clavien H(1992) Longitudinal 
Citation: El Badri D, Rostom S, Bouaddi I, Hassani A, Chkirate B, et al. (2014) Bone Mineral Density in Moroccan Patients with Juvenile Idiopathic Arthritis. J Arthritis 3: 131. doi:10.4172/2167-7921.1000131

Page 5 of 5

monitoring of bone mass accumulation in healthy adolescents: evidence for a marked reduction after 16 years of age at the levels of lumbar spine and femoral neck in female subjects. J Clin Endocrinol Metab 75: 1060-1065.

32. Boot AM, de Ridder MA, Pols HA, Krenning EP, de Muinck Keizer-Schrama SM (1997) Bone mineral density in children and adolescents: relation to puberty, calcium intake, and physical activity. J Clin Endocrinol Metab 82: 57-62.

33. Van Coeverden SC, De Ridder CM, Roos JC, Van't Hof MA, Netelenbos JC, et al. (2001) Pubertal maturation characteristics and the rate of bone mass development longitudinally toward menarche. J Bone Miner Res 16: 774-781.

34. Johnston CC Jr, Miller JZ, Slemenda CW, Reister TK, Hui S, et al. (1992) Calcium supplementation and increases in bone mineral density in children. $\mathrm{N}$ Engl J Med 327: 82-87.

35. Mackelvie KJ, McKay HA, Khan KM, Crocker PR (2001) Lifestyle risk factors for osteoporosis in Asian and Caucasian girls. Med Sci Sports Exerc 33: 18181824. 